\title{
Estimation of genetic parameters of growth traits for direct and maternal effects in Murrah buffalo
}

POOJA JOSHI ( $\sim$ joshi33333puja@gmail.com )

NDRI: National Dairy Research Institute https://orcid.org/0000-0002-5940-2069

G.R. Gowane

National Dairy Research Institute

Rani Alex

National Dairy Research Institute

I.D. Gupta

National Dairy Research Institute

Destaw Worku

Salale University

Linda George

National Dairy Research Institute

Ashish Ranjan

National Dairy Research Institute

Archana Verma

National Dairy Research Institute

\section{Research Article}

Keywords: Animal model, AIREML, Genetic parameters, Growth traits, Maternal effects, Murrah buffalo

Posted Date: February 7th, 2022

DOl: https://doi.org/10.21203/rs.3.rs-1298343/v1

License: (1) This work is licensed under a Creative Commons Attribution 4.0 International License. Read Full License 


\section{Abstract}

An understanding of genetic principles and environment factors affecting the growth traits is needed to implement optimal breeding and selection programs. In this study, total of 18,989 records of body weight were used to estimate genetic parameters of body weight at birth (BW), 3-month (3BW), 6-month (6BW), 9-month (9BW), 12-month (12BW), 18-month (18BW), 24-month (24 BW), 30month (3BW) and 36-month (36BW) of Murrah buffalo at ICAR-NDRI Karnal, Haryana, for the period 1974-2019. The genetic parameters were estimated using average information restricted maximum likelihood (AIREML) procedure by excluding or including maternal effects. Six analytical models were fitted in order to optimize the model for each trait. Most appropriate univariate model was selected based on Log likelihood ratio test (LRT). Influencing factors like calf sex, period of birth, season of birth and dam's parity were investigated. The results showed that the maternal genetic effects, in addition to direct additive effect are also important determinants of the genetic parameter estimates for growth traits in Murrah buffaloes. Total heritability estimates $h^{2} T_{1}$ for $B W, 3 B W$, 6BW, 9BW, 12BW, 18BW, 24BW, 30BW and 36BW were $0.25,0.04,0.14,0.16,0.10,0.15,0.21,0.24$, and 0.23 respectively. Maternal effect was important for birth weight and accounted for $13 \%$ variation through maternal genetic and $5 \%$ variability through maternal permanent environmental effect. Maternal genetic effect was also important and interfered with the estimates of variance ratios in live weight traits owing to large and negative covariance between direct and maternal genetic effects. Direct genetic correlation between body weight traits were positive and high ranging from 0.10 to 0.94 . Results revealed that the Murrah herd has a sizable genetic variability for growth traits and hence there is sufficient scope for selection for achieving better growth rate if selection in this direction is applied. Owing to higher positive genetic correlation of 6BW with later ages, the scope of indirect selection for optimum growth in later ages can be aimed at by selecting animals for their higher 6-month live weight.

\section{Introduction}

Growth traits are amongst the important economic traits of livestock. Animal growing faster commences the reproductive and the productive cycle early hence maximises the net economic return. Decisions about heifer management interact with underlying biological aspects of growth, thereby influencing future profitability of the herd (Mourits et al.,1999). Thus, the growth rates of replacement heifers affect economic returns on dairy farms. Growth traits are affected by the genetic and environmental factor. Maternal effects also contributes to the total variance of the growth traits. The maternal effect refers to the effect of gene of animal's dam influencing the individual's performance during gestation and nursing. Thus, the knowledge of genetic properties of economic traits is the pre-requisite in establishing the selection programme.

India holds the first spot in global market for highest milk production. Murrah buffaloes contribute more than $50 \%$ to the total milk production of the country. Murrah buffalo is the dynamic water buffalo breed, belonging to Haryana and Punjab state of the country. This breed is used extensively in upgradation of the non-descript buffaloes in the country and for improved milk production of dairy buffaloes in other countries viz; Egypt, Bulgaria and Italy. Growth traits in beef cattle has been extensively studied across the world because of the economic value of growth in this beef farming. However, growth in dairy animals has not been studied so extensively, particularly the genetic component of growth. Literature suggested few studies on the estimates of genetic parameters of growth traits using parent offspring method and paternal half sib method (Thiruvenkadan et al.2009; Shahin 2010; Gupta et al.2015). However, they have not tried to partition the total variance into animal's genetic and maternal components. Maternal effects are expressed in the juvenile traits in mammals and they are dependent on the "environment provided by the mother". The maternal effects are a social environment which are partially heritable and are of immense breeding interest in livestock industry. Willham (1972) deduced the various components of the maternal effects, where phenotype of offspring was shown to be made up of direct and maternal additive effects and their covariance. Maternal effect create additional genetic and non-genetic covariances among relatives. Estimation of maternal effects are important as not incorporating them may result in biased estimation of genetic parameters, if the traits are actually affected my maternal effects. Therefore, the present investigation was undertaken to estimate the variance and covariance components in the growth traits of Murrah buffaloes using the animal model with due consideration of maternal effects. Aim of the study is to assess the genetic parameters for the traits and suggest a possible strategy for futuristic breeding program.

\section{Materials And Methods}


Study was conducted in ICAR-National Dairy Research Institute, Karnal during the period extended from year 1974 to 2019 . Total of 18,989 body weight records of Murrah buffaloes starting from time of birth upto 36moths of age were used in the present study.

The geographical location of NDRI livestock farm is at an altitude of 250 meters above the sea level at $29^{\circ} 42^{\prime} \mathrm{N}$ and $72^{\circ} 02 \mathrm{E}$ longitude. Nine different growth traits used for the analysis were birth weight (BW), 3-month weight (3BW), 6-month weight (6BW), 9month weight (9BW), 12-month weight (12BW), 18-month weight(18BW), 24-month weight(24BW), 30-month weight(30BW) and 36month weight(36BW). Murrah buffaloes are maintained in a loose housing system in the herd, fed on good quality green fodder ad libitum and provided with adequate veterinary health and care. Selective breeding policy is practiced with major emphasis on improved progeny performance for milk production. Animals were weighed on regular basis. Birth weight was taken within 24 hours of birth of calf, and 3BW, 6BW, 9BW,12BW, 18BW, 24BW, 30BW and 36BW were taken on exact dates. Number of records, number of sire and dam, least squares means, standard deviations, coefficient of variation for respective traits are summarized in Table 1.

Co(variance) components and heritability estimates were obtained through single trait animal model analysis using average information restricted maximum likelihood (AIREML) approach with various combinations of additive and maternal effects. Log likelihood ratio test(LRT) was used to determine the most suitable model for each trait. Least squares analysis of variance was done to identify the fixed effects that will be used further in the genetic analysis of data. For growth traits, statistical model for least squares analyses included effect of period of birth (10 levels), season of birth (4 levels), sex of the calf ( 2 levels) and parity of the dam (9) as fixed covariates. All the fixed effects were significant $(P<0.05)$ up to 6 months of age. Afterwards, all the effects, except dam's parity, were significant. Only significant effects $(P<0.05)$ were included in the models that were subsequently used for the genetic analysis (Table1).

Six different single-trait linear models that accounts for various combinations of direct and maternal effects were fitted for each trait. Model 1 was the simple animal model with animal additive genetic effect as the only random effect. In model 2 , the maternal additive genetic effect was included as the additional random effect ignoring the covariance between animal direct additive and maternal additive genetic effect $\left(\operatorname{Cov}\left(\mathrm{a}_{\mathrm{m}}, \mathrm{m}_{\mathrm{o}}\right)=\right.$ zero). In model 3 , the maternal additive genetic effect was included as the additional random effect considering the covariance between animal direct additive and maternal additive genetic effect $\operatorname{Cov}\left(a_{m}, m_{0}\right)=A \sigma_{a m}$. Model 4 included permanent environment effect due to dam as an additional random effect other than animal direct effect. In Model 5 , both maternal additive genetic effect and permanent environment effect due to dam were taken as additional random effect ignoring the covariance between animal direct additive and maternal additive genetic effect ( $\left.\operatorname{Cov}\left(\mathrm{a}_{\mathrm{m}}, \mathrm{m}_{\mathrm{o}}\right)=\mathrm{zero}\right)$. In the inclusive Model 6, both maternal additive genetic effect and permanent environment effect due to dam were taken as additional random effect accounting for the covariance between animal direct additive and maternal additive genetic effect $\left(\operatorname{Cov}\left(a_{m}, m_{\circ}\right)\right.$ $\left.=A \sigma_{\mathrm{am}}\right)$.

$$
\begin{aligned}
& \boldsymbol{Y}=\boldsymbol{X} \boldsymbol{\beta}+\boldsymbol{Z}_{\boldsymbol{a}} \boldsymbol{a}+\boldsymbol{e} \\
& \boldsymbol{Y}=\boldsymbol{X} \boldsymbol{\beta}+\boldsymbol{Z}_{\boldsymbol{a}} \boldsymbol{a}+\boldsymbol{Z}_{\boldsymbol{m}} \boldsymbol{m}+\boldsymbol{e} \quad \text { with } \operatorname{Cov}\left(a_{m}, m_{o}=0\right. \\
& \boldsymbol{Y}=\boldsymbol{X} \boldsymbol{\beta}+\boldsymbol{Z}_{\boldsymbol{a}} \boldsymbol{a}+\boldsymbol{Z}_{\boldsymbol{m}} \boldsymbol{m}+\boldsymbol{e} \quad \text { with } \operatorname{Cov}\left(a_{m}, m_{o}\right)=\boldsymbol{A} \sigma_{a m} \\
& \boldsymbol{Y}=\boldsymbol{X} \boldsymbol{\beta}+\boldsymbol{Z}_{\boldsymbol{a}} \boldsymbol{a}+\boldsymbol{Z}_{\boldsymbol{m}} \boldsymbol{m}+\boldsymbol{Z}_{\boldsymbol{p} \boldsymbol{e}} \boldsymbol{p} \boldsymbol{e} \boldsymbol{e} \\
& \boldsymbol{Y}=\boldsymbol{X} \boldsymbol{\beta}+\boldsymbol{Z}_{\boldsymbol{a}} \boldsymbol{a}+\boldsymbol{Z}_{\boldsymbol{m}} \boldsymbol{m}+\boldsymbol{Z}_{\boldsymbol{p} \boldsymbol{e}} \boldsymbol{p} \boldsymbol{e}+\boldsymbol{e} \quad \text { with } \operatorname{Cov}\left(a_{m}, m_{o}=0\right. \\
& \boldsymbol{Y}=\boldsymbol{X} \boldsymbol{\beta}+\boldsymbol{Z}_{\boldsymbol{a}} \boldsymbol{a}+\boldsymbol{Z}_{\boldsymbol{m}} \boldsymbol{m}+\boldsymbol{Z}_{\boldsymbol{p} \boldsymbol{e}} \boldsymbol{p} \boldsymbol{e}+\boldsymbol{e} \quad \text { with } \operatorname{Cov}\left(a_{m}, m_{o}\right)=\boldsymbol{A} \sigma_{a m}
\end{aligned}
$$

where, $\mathbf{Y}$ represents the vector of records; $\boldsymbol{\beta}, \mathbf{a}, \mathbf{m}$, pe and $\mathbf{e}$ were vectors of fixed, direct additive animal genetic, maternal additive genetic, permanent environmental effects of the dam and residual effects, respectively. The $\mathbf{X}, \mathbf{Z}_{\mathbf{a}}, \mathbf{Z}_{\mathbf{m}}$ and $\mathbf{Z}_{\mathrm{pe}}$ were association matrices, A represents a numerator relationship matrix between animals and $\sigma_{\mathrm{am}}$ referred to the covariance between additive direct and maternal genetic effects. 
The average-information restricted maximum likelihood (AIREML) algorithm (Johnson and Thompson, 1995) was employed for estimation of (co)variance components. A value of $10^{-8}$ was used as the convergence criterion for the analysis. LRT was used to select the most appropriate univariate model for each trait (Meyer, 1992). Whenever inclusion of one effect increased the loglikelihood, compared to the model in which it was ignored, the effect was considered to have significant influence. Significance was tested at $\mathrm{P}<0.05$ by comparing differences in log-likelihoods to values for a $\chi^{2}$ distribution with degrees of freedom equal to the difference in the number of (co)variance components fitted for the two models. Genetic, phenotypic and environmental correlations among all the traits mentioned above were estimated by bivariate analysis with starting values derived from the best selected univariate model. The total heritability estimate were calculated by accounting for the maternal effects using Willham (1972) as $\mathrm{h}^{2}{ }_{\mathrm{T} 1}$ and Eaglen and Bijma (2009) as $\mathrm{h}^{2}{ }_{\mathrm{T} 2}$.

\section{$h_{T 1}^{2}=\left[\sigma_{A}^{2}+1.5\left(\sigma_{a m}\right)+0.5\left(\sigma_{M}^{2}\right)\right] / \sigma_{P}^{2}$ $h_{T 2}^{2}=\left[\sigma_{A}^{2}+2\left(\sigma_{a m}\right)+\left(\sigma_{M}^{2}\right)\right] / \sigma_{P}^{2}$}

$\mathrm{h}_{\mathrm{T} 1}^{2}, \mathrm{~h}^{2}{ }_{\mathrm{T} 2}$ is total heritability; $\sigma^{2}{ }_{\mathrm{A}}$ is additive genetic variance, $\sigma^{2}{ }_{\mathrm{M}}$ is additive maternal variance, $\sigma^{2}{ }_{\mathrm{P}}$ is phenotypic variance and $\sigma_{\mathrm{am}}$ is the covariance between additive genetic and maternal effect.

Genetic trend was estimated by regressing the mean breeding values on birth year.

\section{Results And Discussion}

Least squares means along with the standard deviation (S.D.) and percent coefficient of variation (CV\%) for different traits under study are given in Table 1. The least squares means for various traits were $B W=32.45 \pm 0.09 \mathrm{~kg} ; 3 \mathrm{BW}=66.68 \pm 0.31 \mathrm{~kg} ; 6 \mathrm{BW}$ $=110.76 \pm 0.52 \mathrm{~kg} ; 9 \mathrm{BW}=152.15 \pm 0.71 \mathrm{~kg} ; 12 \mathrm{BW}=200.23 \pm 1.01 \mathrm{~kg} ; 18 \mathrm{BW}=277.14 \pm 1.23 \mathrm{~kg} ; 24 \mathrm{BW}=360.40 \pm 1.13 \mathrm{~kg}$; $30 \mathrm{BW}=404.35 \pm 1.31 \mathrm{~kg} ; 36 \mathrm{BW}=458.71 \pm 1.73 \mathrm{~kg}$. The sex of the calf significantly affected all the growth traits except 3BW and $6 \mathrm{BW}$ $(p<0.01, p<0.05)$ as male calves are heavier than female calves. Season of calving also had significant effect on all the traits except 3BW where calves born during winter season were heavier compared to those born in other seasons. This may be due to appropriate temperature and good feeding regime during winter season. Furthermore, period of calving had significantly affected all the growth traits. The effect of period of calving reflects year to year variability with respect to climate change, management practises and feeding. Moreover, in the current study, the effect of dam's parity was significant on early rearing phase i.e. BW, 3BW and 6BW. Birth weight was lower for primiparous dam than those of multiparous. Also with increase in parity number higher birth weight was observed. The effect of dam's parity on BW and other growth traits may be attributed to the maturity status of dams in their advanced parity, they have adequate body capacity leading to better development of foetus.

(Co)variance components and genetic parameters estimated by most appropriate model in univariate analysis for various traits of Murrah buffalo are presented in Table 2. As per LRT, the best model for birth weight (BW) was Model-5, which included direct additive and permanent environmental effects of the dam. For 12BW, Model 1 (a simple animal model) was the best that included only direct additive effect. For rest of the traits (3BW,6BW,9BW,18BW,24BW,30BW and 36BW), Model 3 was the best that includes direct additive effect of dam and covariance between direct genetic and dam's direct additive effect.

\section{Birth weight}

Model-1 gave substantially higher estimate of heritability for birth weight than other models i.e. $0.34 \pm 0.03$, which reduced to $0.18 \pm 0.02$ on addition of maternal genetic effect in Model-2. Also fitting maternal genetic effect resulted in improvement of Log $L$ over Model-1. Direct heritability estimate was increased to $0.24 \pm 0.04$ when direct additive and maternal permanent environmental effect $\left(\mathrm{c}^{2}\right)$ were included in the Model-4, however did not increase the likelihood. Model-5 provided a much better fit to data for birth weight with significantly high likelihood value over all other models for birth weight in Model 5 with the direct additive estimate of $0.19 \pm 0.03$, maternal additive effect ratio $\left(\mathrm{m}^{2}\right) 0.13 \pm 0.04$ and maternal permanent environmental effect $\left(\mathrm{c}^{2}\right) 0.05 \pm 0.03$. In this study low value of maternal permanent environmental effect $\left(c^{2}\right)$ was observed. The buffalo is monotochous animal. The litter size is one 
and in the farm, where data is collected, the calf does not remain for much period with dam. These reasons apart from difficulty in actual partitioning of maternal variance into additive and permanent environment might have reduced the estimate. Moderate estimate of heritability in the present data set indicates further scope of selection for the Murrah buffaloes, however, it must be cautioned that the selection on the birth weight basis is not effective due to significant maternal influence. Lower $\mathrm{h}^{2}$ estimate of birth weight 0.10 with maternal additive $\left(\mathrm{m}^{2}\right) 0.11$ and maternal permanent environmental effect $\left(\mathrm{c}^{2}\right) 0.04$ were reported by Thiruvenkadan et al.(2009) in Murrah buffaloes. It was observed that in literature available, higher estimate of heritability for birth weight in Murrah buffalo were found as compared to our results. The possible reason of inflation may lie with the method of estimation difference with paternal half sib method. Pandya et al.(2015) reported similar $\mathrm{h}^{2}$ estimate (0.18) in Surti buffalo using paternal half-sib method. Higher $\mathrm{h}^{2}$ estimates were reported by Yadav et al.(2001), Gupta et al.(2015) and Shahin (2010) in Murrah buffalo and Soh et al. (2020) in swamp buffalo using paternal half sib method.

\section{Three month body weight}

Model 3 was found to be best for the 3-month body weight with estimates for direct additive $\mathrm{h}^{2} 0.14 \pm 0.05$ and maternal additive effect $\left(\mathrm{m}^{2}\right) 0.18 \pm 0.03$. There was negative covariance between direct genetic and maternal effects. Direct additive $\mathrm{h}^{2}$ estimate of 0.07 in Model1 was fairly consistent across models. estimate were $0.06\left(\mathrm{~h}^{2}\right)$ and $0.02\left(\mathrm{~m}^{2}\right)$ in Model 2 and $0.06\left(\mathrm{~h}^{2}\right)$ and $0.04\left(\mathrm{c}^{2}\right)$ in Model 4, respectively. However, Model 5 had the highest likelihood. The estimates from the inclusive model 5 were $\mathrm{h}^{2}=0.06$, $\mathrm{m}^{2}=0.00$ and $\mathrm{c}^{2}=0.04$. This indicated that the trait had maternal permanent environment alone as the maternal effect. However, we understand that partitioning the maternal effect in to its genetic and environmental component is not easy. Model 6 gave higher estimate of $h^{2}(0.14), m^{2}(0.07)$ and $c^{2}(0.04)$, however these estimates were inflated to adjust the negative covariance between direct and maternal additive effect. Our results were in line with those of Neyser et al.(2012) in Brangus cattle and Akhtar et al. (2012) in Niliravi buffalo for 3-month body weight. Similar estimate in Murrah buffalo where direct $\mathrm{h}^{2}$ estimate of $0.19, \mathrm{~m}^{2}$ as 0.09 and $c^{2}$ as 0.03 were reported by Thiruvenkadan et al.(2009).

\section{Six month and Nine month body weight}

Among six animal models, Model-3 resulted in highest likelihood for both 6 and 9-month body weights. High direct heritability estimate were found for both the traits with $\mathrm{h}^{2}$ as $0.37 \pm 0.08$ and $0.43 \pm 0.11$ for $6 \mathrm{BW}$ and $9 \mathrm{BW}$, respectively. $18 \%$ of total variance was explained by the maternal direct effects for both the traits. However, as the direct additive and maternal covariance was high and negative, the estimates for variance ratios were probably inflated. Very high negative covariance $\left(r_{a m}\right)$ between direct genetic and maternal effect was found which indicate antagonism between the direct effects of dam and animal for these traits. To account for this negative $r_{a m}$ and hence inflated variance ratios, we estimated total heritability (Wilham 1972). The estimate of $h^{2}{ }_{T}$ for 6BW and 9BW were 0.14 and 0.16 respectively. Similar results were reported by Shahin (2010) and Kharzai et al.(2020) using paternal half sib method. The $\mathrm{h}^{2}$ estimate of 0.22 and $0.18, \mathrm{~m}^{2}$ as 0.08 and 0.05 and $\mathrm{c}^{2}$ as 0.03 and 0.03 were reported for $6 \mathrm{BW}$ and 9BW, respectively by Thiruvenkadan et al. (2009) in Murrah buffalo.

\section{Twelve month body weight}

For 12BW Model-1 was found to be superior amongst all animal models based on LRT. As animal became older, the maternal effect lost its impact on the growth of animals. Heritability estimate for yearling weight was $0.10 \pm 0.03$. Low additive variability may be attributed to the environment effect over 12 BW. Adding maternal genetic effect (Model 2) also gave the same estimate of $h^{2} 0.10$ with negligible $\mathrm{m}^{2}$. Model 3 partitioned total variance into $\mathrm{h}^{2} 0.17$ and $\mathrm{m}^{2} 0.04$ with negative high $\mathrm{r}_{\mathrm{am}}$, however, the inflated variance ratios were mostly due to negative $r_{a m}$. Permanent environmental effect was also not significant in Model 4 . No effect of dam's additive and permanent environment effect across all the advanced models was seen on 12BW, indicating independent expression of the direct effect of animal for growth in later stages. Results of our study were in agreement with those of Pandya et al. (2015) and Gupta et al. (2015) but our method of estimation was more appropriate. There was no evidence of maternal effects after 6 month of age indicating animals own genotype is more important and should be considered for selection.

Page 5/11 


\section{Genetic parameters for higher age live weights}

Higher estimate of direct heritability $0.30 \pm 0.08$ was found for both the traits $18 \mathrm{BW}$ and $24 \mathrm{BW}$ with $\mathrm{m}^{2}$ estimate of $0.10 \pm 0.04$ and $0.02 \pm 0.03$, respectively. The estimate of $h^{2}$ for $30 \mathrm{BW}$ and $36 \mathrm{BW}$ were $0.45 \pm 0.10$ and $0.27 \pm 0.08$, respectively, which were higher. However, lower $\mathrm{m} 2$ estimate 0.10 and 0.05 were obtained for 30BW and 36BW (Table2). The estimate of $\mathrm{r}_{\mathrm{am}}$ was significantly higher and negative for all these 4 traits. This estimate has actually inflated the variance ratios and hence the higher estimates of the heritability was observed. To account for the maternal effect, we have estimated the total heritability using Willham (1972) as $h^{2} T_{1}$ and Eaglen and Bijma (2009) as $h^{2} T_{2}$. The estimate for total heritability $h^{2} T_{1}$ after correctly accounting for the maternal effects were $, 0.15,0.21,0.24$ and 0.23 for 18BW, 24BW, 30BW and 36BW respectively and $\mathrm{h}^{2} \mathrm{~T}_{2} 0.13,0.17,0.21,0.24$ for 18BW, 24BW, 30BW and 36BW respectively.

Higher heritability estimates in buffaloes of Murrah breed augurs the scope for selection for higher weights, if selection is implemented in this direction. In accordance with our study, the higher estimate of $\mathrm{h}^{2}$ for 18BW were reported by Tien and Tripathi (1990) and Gurang and Johar, (1983). Similarly, for 36-month body weight, nearly similar estimate (0.23) using animal model was obtained by Akhtar et al. (2012) in Niliravi buffaloes.

\section{Correlation estimates}

The bivariate analysis for estimation of correlation between different economic traits of Murrah buffaloes was done using the most appropriate models from the single-trait analyses. The correlation estimates obtained between different economic traits were positive and moderate to high suggesting selection of any of the trait will have its positive consequence over the other correlated trait (Table 3). Our results of genetic correlation between body weight traits falls within the range of estimates reported by Pandya et al.(2015) in Niliravi buffaloes.

Estimates for direct genetic correlation $\left(r_{g}\right)$ between birth weight and body weight at different ages were low to moderate except very low of 0.03 between BW to 9BW. It ranged from 0.29 between BW and 6BW to 0.61 between BW and 36BW. Our findings were consistent with positive and medium to high genetic correlation estimates of BW with 3BW (0.72), 6BW (0.70), 9BW (0.68) and 12BW (0.52) by Thiruvenkadan et al.(2009). Neyser et al.(2012) also reported high genetic correlation of birth weight with weaning and yearling weight. However, low correlation estimates of birth weight with different ages were reported by Gupta et al.(2015) in Murrah buffaloes and Shahin et al.(2010) in Egyptian buffaloes. We observed very high $\mathrm{r}_{\mathrm{g}}$ estimate between 3BW and body weights at later stages ( 0.92 between 3BW and 6BW, 0.99 between 3BW and 9BW, 0.52 between 3BW and 12 BW, 0.63 between 3BW and 18BW, 0.99 between 3BW and 24BW, 0.75 between 3BW and 30BW and 0.71 between 3BW and 36BW). These results were in agreement with correlation estimates reported by Thiruvenkadan (2009), Neyser (2012) and Pandya (2015). Shahin (2010) reported low correlation estimates between 3BW and other growth traits. Genetic correlation between 6BW and other ages were also high ranging from 0.50 to 0.91 indicating the scope of indirect selection for post-6BW on the basis of $6 \mathrm{BW}$, suggesting that animals with above average 6BW would tend to be above average in genetic merit for 9BW, 12BW, 18BW, 24BW, 30BW and 36BW too. Similar high genetic correlation was observed between other traits 9BW,12BW,18BW,24BW,30BW and 36BW (Table 3). Estimates of maternal genetic correlation were high for BW and 6BW (0.89). For other traits, non-reliable maternal correlation estimates were obtained with high standard error. Most of the phenotypic correlation estimates were lesser than their genetic counterparts (Table 3). Phenotypic correlation between all the body weight traits were positive and medium to large. Selecting animals for their live weights is a difficult task, as the optimum live weight gained is expressed at later ages. However, owing to high genetic correlation estimates of 6BW with later ages live weight, we can suggest use of $6 \mathrm{BW}$ as the criteria for indirect selection for achieving optimum weight at later ages.

\section{Genetic trend of growth trait}

The estimates of annual rates of genetic progress for all the growth traits were positive but low (Table 4). For birth weight and 3month body weight, statistically significant $(p<0.05)$ genetic gain of $9.7 \mathrm{gm} /$ year and $11 \mathrm{gm} /$ year was obtained respectively. For other growth traits, the genetic trend was found to be non-significant for all the body weight traits with gain of $8 \mathrm{gm} / \mathrm{year}, 19 \mathrm{gm} / \mathrm{year}$, 
24gm/year, 53gm/year, 74gm/year, 73gm/year and 110gm/year for 6BW,9BW,12BW,18BW,24BW,30BW and 36BW respectively. The sluggish genetic gain in all growth traits indicates the negligence of these traits while formulation of the breeding strategies.

Therefore, the present result shows that we necessarily need to include these economic traits in our breeding goals.

\section{Conclusions}

Direct heritability estimates were moderate for all growth traits while direct genetic correlation between the different traits were all positive ranging from moderate to high. Results indicates that the Murrah herd has a considerable amount of genetic variability and hence there is adequate scope of genetic gain in growth rate if selection is applied in this direction. We could visibly see the impact of maternal influence on the growth traits, especially at the early ages, influencing the estimates of additive variance. Higher genetic correlation of $6 \mathrm{BW}$ with other body weights in later ages along with high heritability of 0.37 for $6 \mathrm{BW}$ are suggestive of using $6 \mathrm{BW}$ as one of the criteria for selection in the Murrah herd. Exclusion of maternal effects in the model resulted in biased estimates of genetic parameters in Murrah buffalo. Hence, to implement optimum breeding strategies for improvement of Murrah buffalo, maternal effects should be considered.

\section{Declarations}

\section{Acknowledgements}

The authors are thankful to the Director and Head Animal Genetics and Breeding, ICAR-NDRI, Karnal for providing necessary facilities. We deeply acknowledge the support from In-charge of record room and livestock production management section for maintaining farm records.

\section{Funding :}

Our study includes breeding data, so no funding or grants was used.

\section{Conflict of interest:}

The authors declare that they have no conflict of interest.

\section{Ethics approval :}

This study is based on animal breeding data and no experiment animal was used.We have obtained proper permission from the office of In-charge of record room, ICAR-NDRI, Animal Genetics and Breeding Division, Karnal, Haryana, India. Therefore, use of this data in research does not require ethical clearance.

\section{Consent to participate:}

Not applicable (no case study)

\section{Consent for publicatons:}

Not applicable (no case study)

\section{Availability of data and material:}

The data set generated during and /or analyzed during the current study are available from the corresponding author upon reasonable request. 


\section{Code availability :}

Not applicable

\section{Author contributions :}

Archana Verma elaborated the project and was in charge of overall direction, and supervised the work and helped in writing of the manuscript. Pooja Joshi designed the experiment, collected, edited, and analyzed the data and wrote the draft of the manuscript in consultation with authors. G.R. Gowane takes the lead in the interpretation of results, technical details, contributed in the analysis. Rani Alex helped in the technical details and analysis, I.D Gupta helped in writing the manuscript, Destaw Worku helped in analysis and manuscript writing, Linda George and Ashish Ranjan involved in writing the manuscript. All authors read and approved the final manuscript.

\section{References}

1. Akhtar, P., Kalsoom, U., Ali, S., Yaqoob, M., Javed., Babar, M.E., Mustafa, M.I., Sultan, J.I., 2012. Genetic and Phenotypic parameters for growth traits of Niliravi Buffalo Heifers in Pakistan.The J. Ani Pla. Sci. 22(3 Suppl.): 347-352 ISSN: $1018-708$.

2. Bijma, P., 2006. Estimating maternal genetic effects in livestock. J. Anim. Sci. 84:800-806.

3. Cassiano, L.A.P., Mariante, A.D.S., McManus, C., Marques, J.R.F., CostaN, A.D., 2003. Genetic parameters of production and reproduction traits of buffaloes in the Brazilian Amazon. Pesquisa-Agropecuaria-Brasileira.39(5): 451-457.

4. Eaglen, S.A.E., Bijma, P., 2009. Genetic parameters of direct and maternal effects for calving ease in Dutch Holstein-Friesian cattle. J. Dairy Sci., 92: 2229-2237.

5. Gupta, J.P., Sachdeva, G.K., Gandhi, R.S., Chakravarty, A.K., 2015. Developing Multiple-trait prediction models using growth and production traits in Murrah buffaloes. Buffalo Bull.34(3): 347-355.

6. Gurung, B.S., Johar, K.S., 1984.Genetic architecture of body weights in Murrah buffaloes. Indian Vet. J.60: 365-370.

7. Johnson, D.L.,Thompson, R., 1995. Restricted Maximum Likelihood estimation of variance components for univariate animal models using sparse matrix techniques and average information. J. Dairy Sci. $78: 449-456$.

8. Khauzai, A.L.D., 2020. Estimation of genetic parameters for weights at different ages in local Iraqi buffaloes. Plant Archives Vol. 20, Supplement 2,1801-1804.

9. Meyer, K., 1992.Variance components due to direct and maternal effects for growth traits of Australian beef cattle. Livestock Production Science.31:179-204.

10. Mourits, M.C.M., Huirne, R.B.M., Dijkhuizen,A.A., Kristensen, A.R., Galligan, D.T., 1999. Economic optimization of dairy heifer management decisions. Agric. Syst. 61:17-31.

11. Neyser, F.W.C., Wyk. J.B., Fair. M.D., Lubout. P., Crook. B.J., 2012. Estimation of genetic parameters for growth traits in Brangus cattle.S. Afr. J. Anim. Sci., (Suppl. 1).

12. Pandey, H., Tomar, A.K.S., Upadhyay, D., 2015. Effect of environmental factors on first lactation milk yield in Murrah buffaloes. Buffalo Bulletin,34(4): 459-64.

13. Shahin, K.A., Abdallah, O.Y., Fooda, T.A., Mourad, K.A., 2010.Selection indexes for genetic improvement of yearling weight in Egyptian buffaloes. Archiv Tierzucht53:436-446.

14. Soh, S.S., Sailsi, M.S., Saad, M.Z., Goh, Y.M., Yahaya, M.S. Zulkafli H.S., 2020.Heritability Estimation of Birth Weight of Swamp Buffalo in Sabah, Malaysia. J. Buff. Sci.9: 24-28.

15. Thiruvenkadan, A.K., Panneerselvam, S., Rajendran, R., 2009. Non-genetic and genetic factors influencing growth performance in Murrah Buffalos. S. Afr. J. Anim. Sci.39: 102-106.

16. Tien, N.Q., Tripathi, V. N., 1990.Genetic parameters of body weight at different ages and first lactation traits in Murrah buffaloes. Indian Vet. J.67: 821-825.

17. Willham, R.L., 1972. The role of maternal effects in animal breeding: III. Biometrical aspects of maternal effects in animals. J.Ani Sci. 35:1288-1293. 
18. Yadav, B.S., Yadav, M.C., Ashok, S., Khan, F.H., 2001. Murrah buffaloes - I. Birth weight. Buffalo Bull .20: $29-31$.

\section{Tables}

Table 1

Characterstic of data structure for economic traits in Murrah buffalo

\begin{tabular}{|llllllllll|}
\hline Trait & BW & 3BW & 6BW & 9BW & 12BW & 18BW & 24BW & 30BW & 36BW \\
\hline Period & $* *$ & $* *$ & $* *$ & $* *$ & $* *$ & $* * *$ & $* *$ & $* *$ & $* *$ \\
\hline Season & $* *$ & & $* *$ & $* *$ & $*$ & $* *$ & $*$ & $* * *$ & $* *$ \\
\hline Sex & $* *$ & & & $*$ & $* *$ & $* *$ & $* * *$ & $* * *$ & $* *$ \\
\hline Parity & $* *$ & $*$ & $* *$ & & & & & & \\
\hline No. of records & 3754 & 2020 & 2088 & 1667 & 2013 & 1983 & 1975 & 1764 & 1725 \\
\hline No. of sires with progeny & 371 & 250 & 293 & 287 & 305 & 305 & 300 & 283 & 287 \\
\hline No. of dams with progeny & 1643 & 1117 & 1182 & 1049 & 1210 & 1212 & 1206 & 1115 & 1077 \\
\hline LSM(kg) & 32.45 & 66.68 & 110.76 & 152.15 & 200.23 & 277.14 & 360.40 & 404.35 & 458.71 \\
\hline S.D. (kg) & 4.93 & 15.42 & 21.01 & 32.20 & 44.57 & 50.71 & 56.17 & 55.57 & 59.87 \\
\hline CV\% & 14.88 & 24.06 & 18.96 & 21.74 & 22.72 & 18.80 & 16.22 & 13.85 & 12.80 \\
\hline
\end{tabular}

LSM=Least squares mean, S.D.=Standard Deviation, $C V=$ Coefficient of variation

Birth weight; 3BW=3month weight; $6 \mathrm{BW}=6$ month weight; $9 \mathrm{BW}=9$ month weight; $12 \mathrm{BW}=12$ month weight; 18BW=18month weight; $24 \mathrm{BW}=24$ month weight; 30BW=30 month weight; 36BW=36 month weight

Figures in superscript within the column *indicates significant at $\mathrm{p}<0.05$, $* *$ indicates significant at $\mathrm{p}<0.01$.

Table 2

Estimates of parameters for different economic traits from univariate analysis in Murrah buffalo 


\begin{tabular}{|c|c|c|c|c|c|c|c|c|c|}
\hline Trait & BW & 3BW & $6 \mathrm{BW}$ & 9BW & 12BW & 18BW & 24BW & 30BW & 36BW \\
\hline Model & 5 & 3 & 3 & 3 & 1 & 3 & 3 & 3 & 3 \\
\hline$\sigma_{a}^{2}$ & 4.70 & 28.61 & 170.40 & 460.79 & 198.30 & 796.27 & 973.64 & 1347.16 & 1002.83 \\
\hline$\sigma_{m}^{2}$ & 3.20 & 19.91 & 81.60 & 189.25 & - & 258.04 & 81.72 & 302.44 & 191.85 \\
\hline$s_{a m}$ & - & -19.91 & -98.10 & -259.62 & - & -354.88 & -223.13 & -508.68 & -184.46 \\
\hline$\sigma_{c}^{2}$ & 1.25 & - & - & - & - & - & - & - & - \\
\hline$\sigma_{e}^{2}$ & 15.78 & 175.30 & 301.38 & 668.84 & 1798.40 & 1913.44 & 2372.77 & 1854.61 & 2492.91 \\
\hline$\sigma_{p}^{2}$ & 24.93 & 203.91 & 455.28 & 1059.62 & 1996.71 & 2612.87 & 3204.99 & 2995.53 & 3503.13 \\
\hline$h^{2}$ & $\begin{array}{l}0.19 \\
\pm 0.03\end{array}$ & $0.14 \pm 0.05$ & $0.37 \pm 0.08$ & $0.43 \pm 0.11$ & $0.10 \pm 0.03$ & $0.30 \pm 0.08$ & $0.30 \pm 0.08$ & $0.45 \pm 0.10$ & $0.27 \pm 0.08$ \\
\hline $\mathrm{m}^{2}$ & $0.13 \pm 0.04$ & $\begin{array}{l}0.10 \\
\pm 0.04\end{array}$ & $0.18 \pm 0.05$ & $0.18 \pm 0.06$ & - & $0.10 \pm 0.04$ & $0.02 \pm 0.03$ & $0.10 \pm 0.05$ & $0.05 \pm 0.04$ \\
\hline$c^{2}$ & $0.05 \pm 0.03$ & - & - & - & - & - & - & - & - \\
\hline$h^{2}{ }^{2}$ & 0.25 & 0.04 & 0.14 & 0.16 & 0.10 & 0.15 & 0.21 & 0.24 & 0.23 \\
\hline$h^{2}{ }_{T 2}$ & 0.32 & 0.04 & 0.12 & 0.12 & 0.10 & 0.13 & 0.17 & 0.21 & 0.24 \\
\hline Log-L & -7398.70 & -5978.71 & -6885.01 & -6289.53 & -7801.95 & -8162.18 & -8309.17 & -7359.32 & -7362.81 \\
\hline
\end{tabular}

$\sigma^{2}{ }_{\mathrm{a}}, \sigma_{\mathrm{m},}^{2} \sigma_{\mathrm{am}}, \sigma_{\mathrm{c}}^{2} \sigma_{\mathrm{e},}^{2} \sigma_{\mathrm{p}}^{2}$ are additive direct, additive maternal, additive direct maternal covariance, maternal permanent environment, residual variance and phenotypic variance respectively. $\boldsymbol{h}^{2}$ is direct heritability, $\boldsymbol{m}^{2}$ is maternal additive effect, $\mathrm{c}^{2}$ is $\boldsymbol{\sigma}^{2} \mathrm{c}$ $\sigma_{\mathrm{p}}^{2} \mathbf{h}^{2}{ }_{\mathrm{T} 1}$ and $\mathbf{h}^{2}{ }_{\mathrm{T} 2}$ is total heritability and Log-L is log-likelihood for the best model obtained from AIREML.

Table 3

Estimates of genetic correlation $r_{g}$ (above the diagonal) and phenotypic $r_{p}$ (below the diagonal) for different economic traits 


\begin{tabular}{|c|c|c|c|c|c|c|c|c|c|}
\hline Trait & BW & 3BW & $6 \mathrm{BW}$ & 9BW & 12BW & 18BW & 24BW & 30BW & 36BW \\
\hline BW & 1 & $0.33 \pm .23$ & $0.29 \pm 0.17$ & $0.03 \pm 0.19$ & $0.28 \pm 0.19$ & $0.17 \pm .16$ & $0.40 \pm 0.13$ & $0.38 \pm 0.14$ & $0.61 \pm 0.14$ \\
\hline 3BW & $0.26 \pm 0.02$ & 1 & $0.92 \pm 0.16$ & $0.99 \pm 0.27$ & $0.52 \pm 0.28$ & $0.63 \pm 0.29$ & $1 \pm 0.28$ & $0.75 \pm 0.28$ & $0.71 \pm 0.27$ \\
\hline 6BW & $0.20 \pm 0.02$ & $0.52 \pm 0.02$ & 1 & $0.91 \pm 0.09$ & $0.53 \pm 0.16$ & $0.50 \pm 0.17$ & $0.49 \pm 0.18$ & $0.50 \pm 0.16$ & $0.39 \pm 0.18$ \\
\hline 9BW & $0.12 \pm 0.03$ & $0.32 \pm 0.03$ & $0.62 \pm 0.01$ & 1 & $0.78 \pm 0.11$ & $0.72 \pm 0.14$ & $0369 \pm 0.16$ & $0.23 \pm 0.19$ & $0.23 \pm 0.19$ \\
\hline 12BW & $0.08 \pm 0.02$ & $0.24 \pm 0.03$ & $0.45 \pm 0.02$ & $0.68 \pm 0.01$ & 1 & $0.80 \pm 0.09$ & $0.67 \pm 0.14$ & $0.39 \pm 0.18$ & $0.48 \pm 0.17$ \\
\hline 18BW & $0.16 \pm 0.02$ & $0.27 \pm 0.03$ & $0.42 \pm 0.02$ & $0.52 \pm 0.02$ & $0.69 \pm 0.01$ & 1 & $0.90 \pm 0.08$ & $0.74 \pm 0.10$ & $0.80 \pm 0.10$ \\
\hline 24BW & $0.13 \pm 0.02$ & $0.22 \pm 0.03$ & $0.32 \pm 0.03$ & $0.43 \pm 0.02$ & $0.45 \pm 0.02$ & $0.66 \pm 0.01$ & 1 & $0.88 \pm 0.06$ & $0.96 \pm 0.07$ \\
\hline 30BW & $0.18 \pm 0.02$ & $0.20 \pm 0.03$ & $0.36 \pm 0.02$ & $0.34 \pm 0.02$ & $0.41 \pm 0.02$ & $0.52 \pm 0.10$ & $0.66 \pm 0.01$ & 1 & $0.89 \pm 0.06$ \\
\hline 36BW & $0.21 \pm 0.03$ & $0.22 \pm 0.03$ & $0.29 \pm 0.03$ & $0.34 \pm 0.03$ & $0.34 \pm 0.02$ & $0.41 \pm 0.02$ & $0.56 \pm 0.02$ & $0.68 \pm 0.01$ & 1 \\
\hline
\end{tabular}

Table 4

Genetic trend of various growth traits

\begin{tabular}{|llll|}
\hline Trait & Genetic trend(gm/year) & Trait & Genetic trend(gm/year) \\
\hline BW & $9.7 \pm 0.004^{\star}$ & $18 \mathrm{BW}$ & $53 \pm 0.21$ \\
\hline 3BW & $11 \pm 0.005^{\star}$ & $24 \mathrm{BW}$ & $74 \pm 0.21$ \\
\hline 6BW & $8 \pm 0.01$ & $30 \mathrm{BW}$ & $73 \pm 0.06$ \\
\hline 9BW & $19 \pm .39$ & $36 \mathrm{BW}$ & $11 \pm 0.05$ \\
\hline 12BW & $24 \pm 0.32$ & & \\
\hline
\end{tabular}

Figures in superscript within the column *indicates significant at $p<0.05$,** 